\title{
Comparison of airflow and particulate matter transport in multi-room buildings for different natural ventilation patterns
}

\author{
Hong-Ming Kao, Tsang-Jung Chang * Yi-Fang Hsieh, Chia-Ho Wang, Cheng-I. Hsieh \\ Department of Bioenvironmental Systems Engineering, National Taiwan University, Taipei, 10617, Taiwan, ROC
}

\section{A R T I C L E I N F O}

\section{Article history:}

Received 17 September 2008

Received in revised form 13 April 2009

Accepted 27 April 2009

\section{Keywords:}

Natural ventilation

Airflow characteristics

Particulate matter

Multi-room building

$\mathrm{PM}_{10} / \mathrm{PM}_{2.5} / \mathrm{PM}_{1}$ removal

\begin{abstract}
A B S T R A C T
This study numerically investigates airflow characteristics and particulate matter (PM) transport in multi-room buildings for different natural ventilation patterns with the same air change rate. Four typical natural ventilation patterns (full-open, pass-through, right short-circuit and left short-circuit), representing the ratios of the outlet-to-inlet opening size ranging from 1.67 to 0.17 , are considered to study multi-room airflow characteristics. A measured indoor $\mathrm{PM}_{10}$ profile in Taipei Metropolis is input into the above four ventilation patterns as the initial condition of the PM size distribution. The time variation of indoor $\mathrm{PM}_{10} / \mathrm{PM}_{2.5} / \mathrm{PM}_{1}$ concentrations in each room for various ventilation patterns is next investigated. The effect of ventilation pattern on particle removal mechanism is emphasized. The results show that although the air change rate of the building is the same, airflow characteristics and PM transport behaviors are quite different for various ventilation patterns. The removal efficiencies of $\mathrm{PM}_{10}$ for the four ventilation patterns are all found to be much better than those of $\mathrm{PM}_{2.5}$ and $\mathrm{PM}_{1}$. Particle escape is the major mechanism to remove PM for rooms with double-sided ventilation, whereas particle deposition is important for single-sided ventilation rooms.
\end{abstract}

(c) 2009 Elsevier B.V. All rights reserved.

\section{Introduction}

In East Asia, due to the living habits and cooking style, indoor airborne particulate matter (PM) levels are found to be about 2-4 times higher than those in the homes in western countries [1]. As PM has been found to arouse adverse impact on human beings, especially the finer particle fraction of $\mathrm{PM}_{10}$ (aerodynamic diameter smaller than $10 \mu \mathrm{m}$ ) such as $\mathrm{PM}_{2.5}$ and $\mathrm{PM}_{1}$ (smaller than 2.5 and $1 \mu \mathrm{m}$ ) [2,3], the studies on indoor air cleaning procedure of $\mathrm{PM}_{10}, \mathrm{PM}_{2.5}$ and $\mathrm{PM}_{1}$ are critical in East Asia to promote a more comfortable and healthy indoor environment. In addition, natural ventilation is now commonly used for indoor ventilation worldwide, because it can dilute and remove pollutants emitted from indoor sources without energy consumption. The quality of natural ventilation strongly depends on indoor ventilation pattern. Different natural ventilation patterns give different $\mathrm{PM}_{10} / \mathrm{PM}_{2.5} / \mathrm{PM}_{1}$ removal ability and result in different $\mathrm{PM}$ suspension profiles. To minimize exposure to indoor PM with less energy use, further investigations on the effect of natural ventilation pattern in connection with $\mathrm{PM}_{10}, \mathrm{PM}_{2.5}$ and $\mathrm{PM}_{1}$ removal are necessary in East Asia.

\footnotetext{
* Corresponding author. Tel.: +8862 23622977; fax: +886223635854

E-mail address: tjchang@ntu.edu.tw (T.-J. Chang).
}

Academic studies regarding PM transport in indoor environment have been mostly conducted by experiments [4-8]. In general, these experiments can provide useful knowledge of airflow and PM transport behaviors on the sample points for given experimental configurations. Nevertheless, it is very difficult to simultaneously measure temporal and spatial information on airflow velocity distributions, PM size and concentration distributions in the entire building for any specific physical configurations. Thanks to the great development of computing facilities, computational fluid dynamics (CFD) solutions have become more adequate and convenient for analyzing PM transport behaviors within a building. Since the 1990 s, several CFD works [9-22] have successfully investigated indoor airflow and PM transport, which mainly focused on single room or two-room environment. For example, Lu and Howarth [9] and Lu et al. [10] developed a pioneering CFD model to predict aerosol particle deposition and suspension in a two-zone chamber. Zhang and Chen [11] included large eddy simulation in their CFD model for indoor airflow computation, and Jiang and Chen [12] further simulated the turbulent airflow field in a single-opening house and correctly predicted indoor airflow velocities and ventilation rates. Posner et al. [13] and Lee and Awbi [14] compared their measured and simulated results for indoor airflow in a single test room equipped with an internal partition. Zhao et al. [15] compared indoor particle concentrations and deposition characteristics in a single room with different ventilation method by CFD. Beghein et al. [16] performed 
large eddy simulation to study particle motions in a single room. Chang et al. [19] numerically investigated the effect of ventilation pattern on $\mathrm{PM}_{10} / \mathrm{PM}_{2.5} / \mathrm{PM}_{1}$ transport behavior in a naturally ventilated two-room building. Chang and $\mathrm{Hu}$ [20] numerically studied the transport mechanism of size-dependent airborne particulate matters in partitioned indoor environment. Lai et al. [21] used an Eulerian-type drift-flux model to evaluate indoor airflow and particle dispersion in a two-zone chamber. Chao et al. [22] simulated transport and removal characteristics of expiratory droplets in a single room with furniture.

The above CFD studies of indoor air environment are all restricted to single room or two-room buildings. However, most of the buildings worldwide are divided into multi-room areas, which use indoor partitions to separate the entire building into several isolated spaces. Chang et al. [23] have attempted to study the effect of indoor partition on transport behaviors of indoor airflow and size-dependent PM in multi-room buildings. They concluded that indoor airflow characteristics and PM removal behaviors in a multi-room building are quite different from those in a single room building. Nevertheless, their work only targeted on one type of ventilation pattern. Therefore, the aim of this study is to extend the numerical work of Chang et al. [23] to more complicated ventilation patterns with the same air change rate. The positions of inlet and outlet openings are modified in such a way that four cross-flow displacement ventilation patterns, i.e., full-open, passthrough, right short-circuit and left short-circuit ventilation, have been established for the purpose of studying indoor airflow characteristics in multi-room buildings. A measured indoor $\mathrm{PM}_{10}$ profile in Taipei Metropolis is next input into the above four ventilation patterns as the initial condition of the PM size distribution to study indoor $\mathrm{PM}_{10} / \mathrm{PM}_{2.5} / \mathrm{PM}_{1}$ removal behaviors in multi-room buildings. The effect of ventilation pattern on particle removal mechanism is analyzed.

\section{Numerical methodology}

In this study, two numerical models are adopted to simulate the above four ventilation patterns. First, a 3-D turbulent flow model is required to simulate indoor airflow field. Next, a Lagrangian particle trajectory tracking model is built to figure out particle behaviors over the simulated airflow field. These two models are described in the following.

\subsection{Three-dimensional indoor turbulent flow model}

Since the $1990 \mathrm{~s}$, large eddy simulation (LES) has received more and more attention and has been successfully applied to several natural ventilation problems [11,12]. The filtered continuity equation and momentum equation in LES are listed below

$\frac{\partial \bar{u}_{i}}{\partial x_{i}}=0$

and

$\frac{\partial \bar{u}_{i}}{\partial t}+\frac{\partial \bar{u}_{i} \bar{u}_{j}}{\partial x_{j}}=-\frac{1}{\rho} \frac{\partial \bar{p}}{\partial x_{i}}+v \frac{\partial^{2} \bar{u}_{i}}{\partial x_{j} \partial x_{j}}-\frac{\partial \tau_{i j}}{\partial x_{j}}$

where the over bar "-" represents spatial filtering, $\bar{u}_{i}$ is the component of filtered instantaneous fluid velocity in the $x_{i}$ direction, $\bar{p}$ is fluid pressure, $\rho$ is fluid density, and $v$ is fluid kinematic viscosity, and $\tau_{i j}\left(=-2(C s \Delta)^{2}\left(2 \tilde{S}_{i j} \cdot \tilde{S}_{i j}\right)^{1 / 2}\right)$ represents the subgrid-scale Reynolds stresses, which is responsible of momentum exchanges between the subgrid-scale eddies and filtered-scale eddies. In the subgrid-scale Reynolds stresses, $\tilde{S}_{i j}$ is fluid strain rate, and $\Delta=\left(\Delta x_{i} \Delta x_{j} \Delta x_{k}\right)^{1 / 3}$ is filtered grid width in three dimensions. $C_{s}$, a Smagorinsky constant and usually between
0.1 and 0.2 [11], is 0.15 in the present study. It should be noted that since LES produces time-dependent solutions, the time-averaged velocities $\left\langle\bar{u}_{i}\right\rangle$ can be obtained by statistical analysis of the instantaneous velocities $\bar{u}_{i}$ according to $\bar{u}_{i}=\left\langle\bar{u}_{i}\right\rangle+\bar{u}_{i}^{\prime}$, where $\bar{u}_{i}^{\prime}$ denotes the turbulent components of the filtered velocities.

For the present study, the finite volume mesh is developed for the discretization of governing equations. A second-order upwind scheme is used to discretize the convention term. The central difference scheme is adopted to discretize the diffusion term and pressure term. A second-order Adams-Bashforth scheme is considered to discretize time. The SIMPLE algorithm (Launder and Spalding [24]) is used to couple pressure and velocity. Three kinds of airflow boundary conditions are considered, including the inflow boundary, outflow boundary and solid surface boundary. At the inflow boundaries, the velocities of inflow have to be defined. At the outflow boundaries, the gradients for all flow variables except pressure are assumed as zero. Non-slip condition is applied on indoor solid surfaces. Near the regions of indoor solid surfaces, the wall function is adopted. The other numerical details can be found in Chang et al. $[19,23]$.

\subsection{Three-dimensional Lagrangian particle tracking model}

In the present study, the PM size that we focus on is ranging from 0.1 to $10 \mu \mathrm{m}$. Under such particle size range, time series of instantaneous particle positions can be obtained by numerical integration of the following three-dimensional differential equations, which include the gravitational force, $F_{G}$, the drag force, $F_{D}$, the Saffman lift force, $F_{S}$, and the Brownian motion force, $F_{B}$. $[20,25-27]$

$$
\begin{aligned}
\pi \rho_{p} d_{p}^{3} \frac{d u_{i}^{p}}{d t}= & F_{G}+F_{D}+F_{S}+F_{B} \\
= & \frac{1}{6} \pi d_{p}^{3}\left(\rho_{p}-\rho\right) g_{i} \delta_{i 3}-\frac{1}{6} \pi \rho_{p} d_{p}^{3} \cdot \frac{1}{\tau}\left(u_{i}^{p}-\bar{u}_{i}\right) \\
& -\frac{1}{6} \pi \rho_{p} d_{p}^{3} \frac{5.188 v^{1 / 2} d_{i j}}{S d_{p}\left(d_{l k} d_{k l}\right)^{1 / 4}}\left(u_{j}^{p}-\bar{u}_{j}\right) \\
& +\frac{1}{6} \pi \rho_{p} d_{p}^{3} G_{i} \sqrt{\frac{\pi S_{0}}{\Delta t}}
\end{aligned}
$$

and

$\frac{d x_{i}}{d t}=u_{i}^{p}$

where $\bar{u}_{i}$ is filtered instantaneous fluid velocity, $\bar{u}_{i}^{p}$ is particle velocity, $\rho$ is fluid density, $\rho_{p}$ is particle density, $x_{i}$ is coordinate of particles, $t$ is time, $d_{p}$ is particle diameter, $S$ is the density ratio between particle and adjacent fluid, $v$ is kinematic viscosity, $\delta$ is unit delta function, $\tau$ is relaxation time of the particle, and $d_{i j}$ $\left[=\left(u_{i, j}+u_{j, i}\right) / 2\right]$ is the deformation rate tensor. The Brownian motion force is modeled as Gaussian white noise random process, where $G_{i}$ is zero-mean, unit variance independent Gaussian random number, $\Delta t$ is time step, and $S_{0}$ is spectral intensity [25]. Two kinds of particle boundary condition are used. Trap boundary represents that once a particle touches it, the particle is trapped, and particle tracking process would cease. Walls, floors and ceilings in the building are regarded as the trap boundary. Outflow boundary is used for all the building exterior outlets such as windows and doors. When a particle passes through the outflow boundary, the particle tracking is terminated. The numerical details of solving Eqs. (3) and (4) and the assumptions of the numerical simulation can be found in Chang and $\mathrm{Hu}[20]$.

Based on the above calculated instantaneous particle trajectories at each time step, the numerical particle mass concentration 
(C) in each room at each tracking minute can be determined by using

$C=\frac{M_{S}}{V}$

where $M_{S}$ is the total mass of suspended particles in each room, and $V$ denotes the volume of each room.

\subsection{Model verification}

To make sure the accuracy of the numerical model developed herein, model verification should be firstly conducted. For the 3-D turbulent flow model, it has been validated with the measured LDV indoor air velocities in a two-room chamber (Posner et al. [13]) and the measured airflow velocities in a three-room full-scale building (Chung [28]). In Fig. 1 of Chang et al. [23], the vertical mean velocities along the inlet centerline and the mid-partition height were obtained from their numerical simulation. The average relative error between the numerical simulation and the measured result of Posner et al. [13] was less than 5\%. In Fig. 2 of Chang et al.
[23], the average relative error between the simulated airflow velocities and Chung's [28] experimental data was less than $10 \%$. Agreement between the numerical and measured results is quite satisfactory.

On the other hand, the 3-D Lagrangian particle tracking model has been validated by the measured indoor mass concentrations of a full-scale two-zone building (Lu et al. [10]). Comparisons of the PM mass concentrations in both zones between the numerical simulations and the full-size experiments for various cases have been shown in Fig. 3 of Chang et al. [19] and Fig. 4 of Chang et al. [23]. Good agreement of the PM mass concentrations between the simulated and measured data can also be found.

\section{Specifications of numerical scenario simulations}

The multi-room building used for numerical scenario simulations is an one-story residential RC building. The geometrical configuration of the building is displayed in Fig. 1. The building has dimensions of $10.0 \mathrm{~m}$ in length, $10.0 \mathrm{~m}$ in width and $4.5 \mathrm{~m}$ in height. The layout of this building is commonly seen in East Asia.
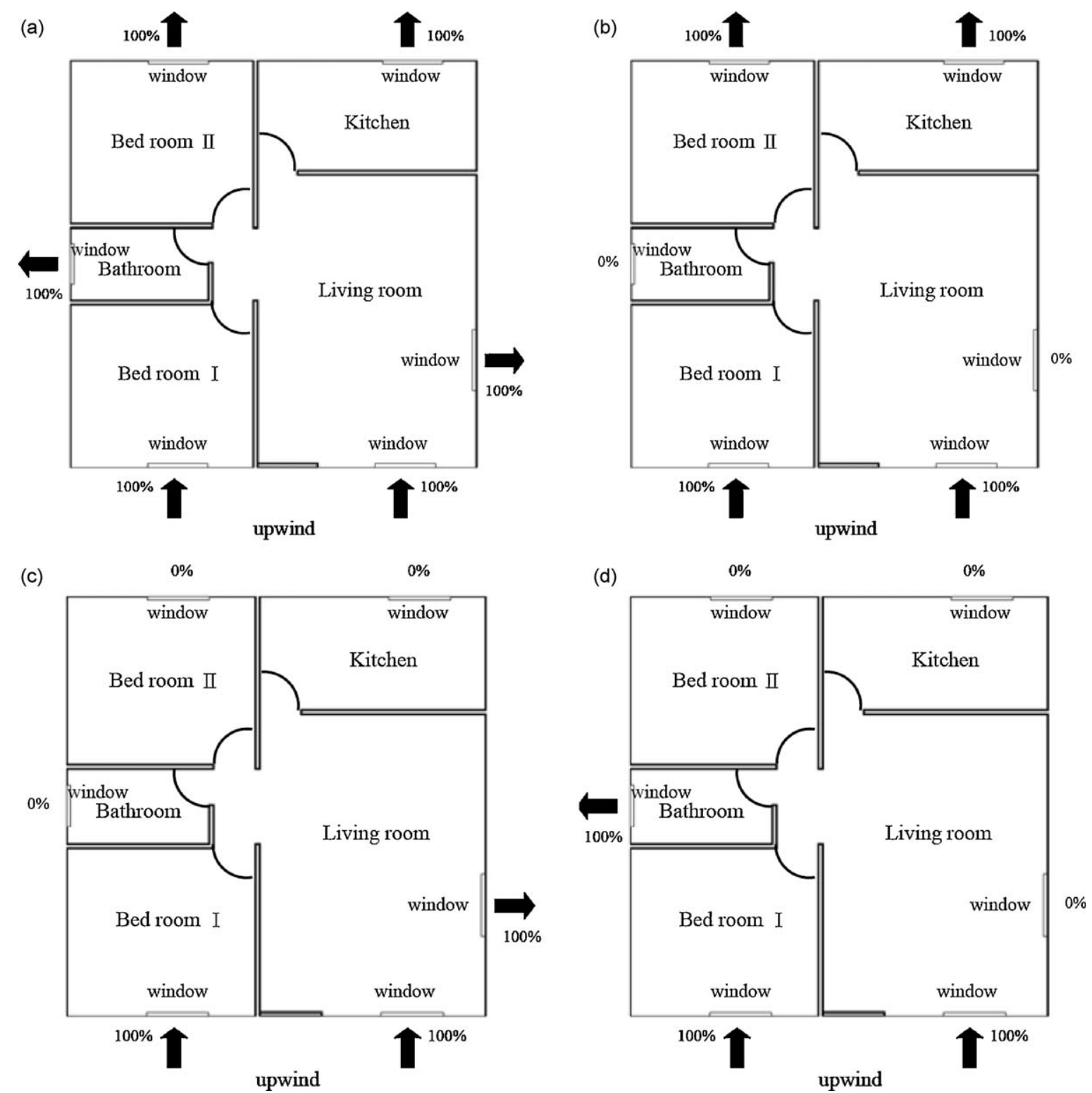

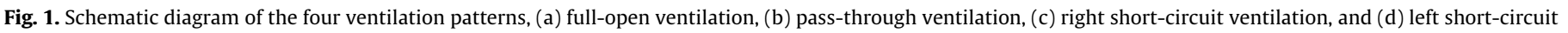
ventilation. 
(a)
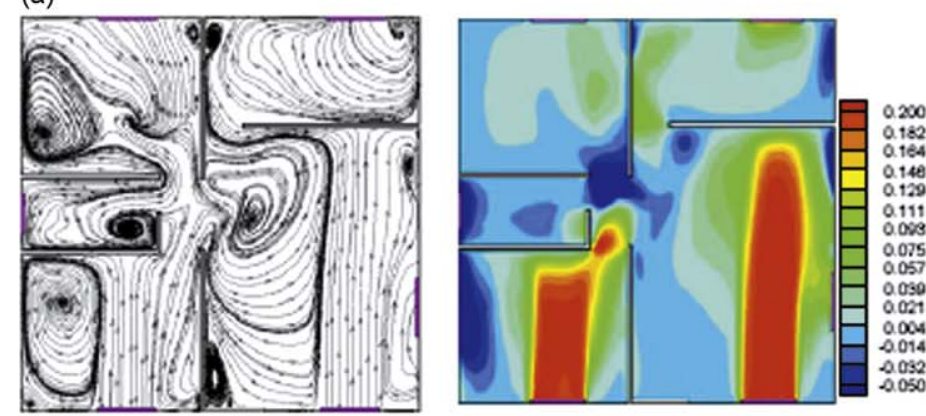

(b)

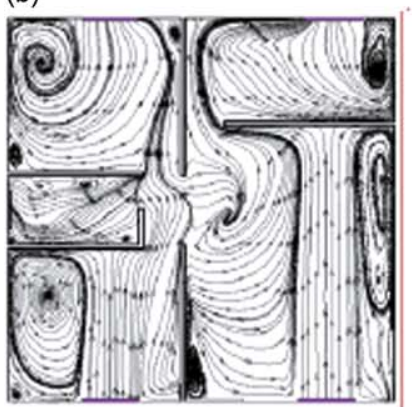

(c)

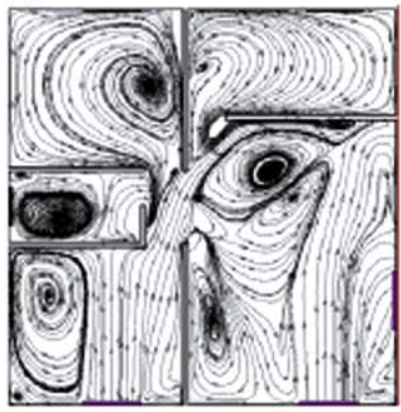

(d)

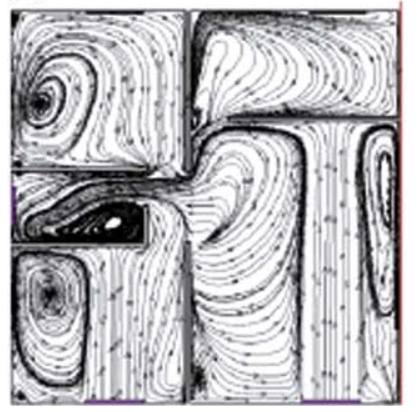

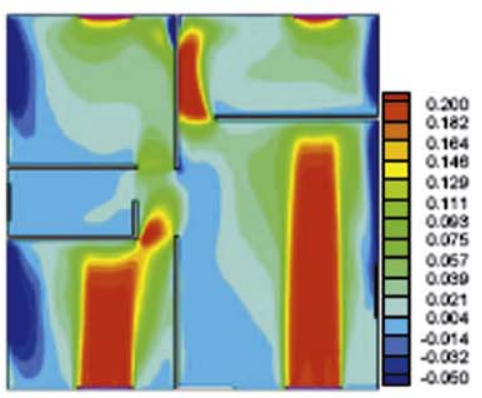
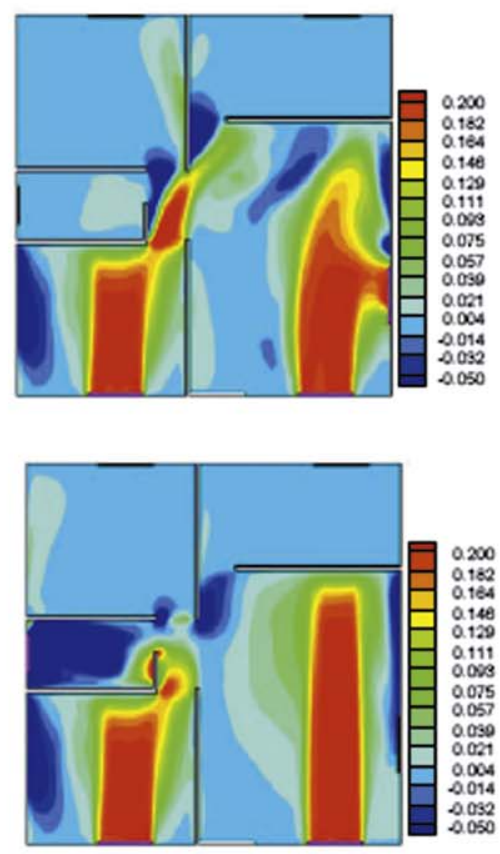
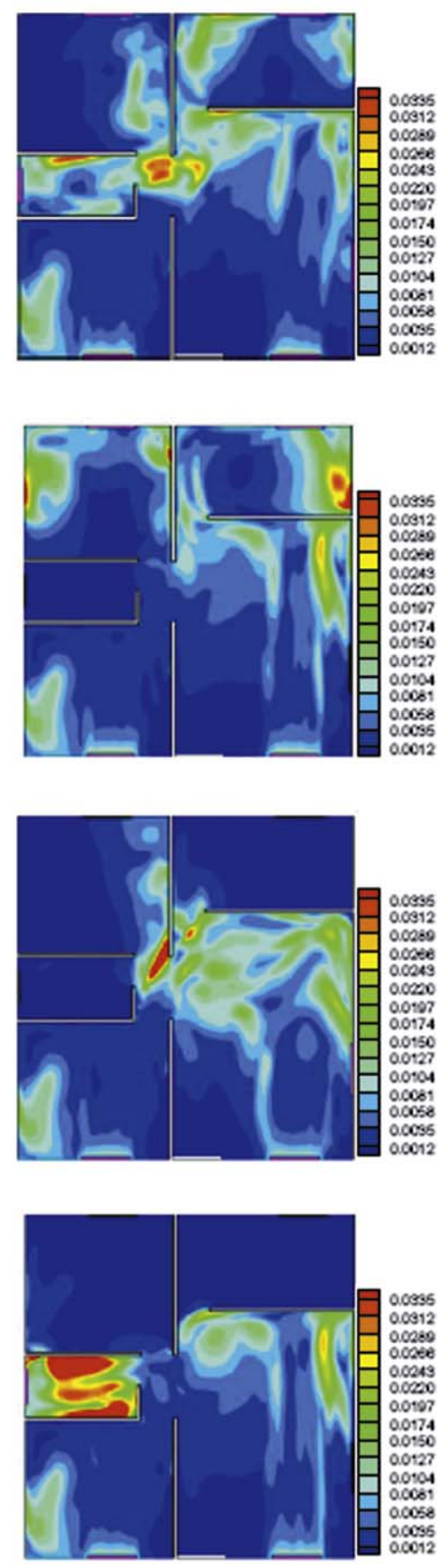

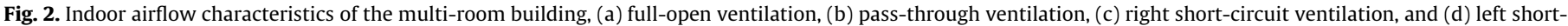
circuit ventilation.

There are five rooms inside the building, including one living room, one kitchen, two bedrooms and one bathroom. The thickness of all the walls and indoor partitions of the building is set to be $0.3 \mathrm{~m}$. Each room has at least one door and one window for natural ventilation. Only natural (window) ventilation is considered. The airflow in the building is assumed $20^{\circ} \mathrm{C}$ iso-thermal. The dimension of all the doors in the building is $1.0 \mathrm{~m}$ in width and $1.8 \mathrm{~m}$ in height. The size of the window in the bathroom is only $1.0 \mathrm{~m}$ in width, $0.5 \mathrm{~m}$ in height and $1.8 \mathrm{~m}$ high from the floor. Other windows have the same size of $1.5 \mathrm{~m}$ in width, $1.0 \mathrm{~m}$ in height and $1.1 \mathrm{~m}$ high from the floor. Outdoor air enters through the windows in the living room and bedroom I. Thus, the total inlet opening size is $3.0 \mathrm{~m}^{2}$. The velocity of the inflow air is $0.2 \mathrm{~m} \mathrm{~s}^{-1}$, giving approximately $5 \mathrm{~h}^{-1}$ air change rate of the entire building. Four typical types of cross-flow displacement ventilation, i.e., full-open, pass-through, right short-circuit and left short-circuit ventilation, as shown in Fig. 1, are established for the purpose of investigating transport behaviors of indoor airflow and size-dependent PM in multi-room buildings.

In Fig. 1a, all the windows are open for full-open ventilation in such a way that all of the rooms receive double-sided ventilation. As summarized in Table 1, the ratio of the outlet-to-inlet opening size is 1.67 . It can be seen from Fig. $1 \mathrm{~b}$ that, regarding pass-through ventilation, the flow path in the lateral direction is restricted, resulting in a special airflow pattern just like a piston flow. The bathroom is given by single-sided ventilation. Other rooms remain 
Table 1

Opening and airflow characteristics of the four ventilation patterns used.

\begin{tabular}{lllll}
\hline Ventilation pattern & $\begin{array}{l}\text { Total outlet } \\
\text { opening } \\
\text { size }\left(\mathrm{m}^{2}\right)\end{array}$ & $\begin{array}{l}\text { Total inlet } \\
\text { opening } \\
\text { size }\left(\mathrm{m}^{2}\right)\end{array}$ & $\begin{array}{l}\text { Outlet-to-inlet } \\
\text { opening size } \\
\text { ratio }\end{array}$ & $\begin{array}{l}\text { No. of } \\
\text { single-sided } \\
\text { ventilation } \\
\text { room }\end{array}$ \\
\hline Full-open & 5.0 & 3.0 & 1.67 & 0 \\
Pass-through & 3.0 & 3.0 & 1.00 & 1 \\
Right short-circuit & 1.5 & 3.0 & 0.50 & 3 \\
Left short-circuit & 0.5 & 3.0 & 0.17 & 2 \\
\hline
\end{tabular}

double-sided ventilation. The ratio of the outlet-to-inlet opening size is thus reduced to 1.00 . In Fig. 1c, in the case of right shortcircuit ventilation, there is only one outflow window adjacent to the inflow window in the living room, giving a so-called shortcircuit effect. Single-sided ventilation can be found in the bathroom, bedroom II and kitchen. The ratio of the outlet-to-inlet opening size is further reduced to 0.50 . As to left short-circuit ventilation, another type of short-circuit ventilation in Fig. $1 \mathrm{~d}$ is observed. The bathroom receives good double-sided airflow exchange because the only outlet is in the bathroom. The kitchen and bedroom II both have single-sided ventilation. The ratio of the outlet-to-inlet opening size is only 0.17 .

For each ventilation pattern, the large eddy simulation with a non-uniform hexahedral grid of 617,000 $(106 \times 104 \times 56)$ meshes is conducted. ICEM CFD Hexa [29] is used for non-uniform grid generation, which is a semi-automated meshing module. Special grid refinement is set for all of the regions near indoor solid surfaces, such as ceilings, floors, walls, and indoor partitions. The smallest mesh used herein is $0.04 \mathrm{~m}$, which is only one order higher than the Kolmogorov length scale. After carrying out LES for several flow-through times ( $50 \mathrm{~s}$ ) to ensure that the final timeaveraged results are independent of the initial conditions, the time-averaged velocities and turbulent statistics are collected over $120 \mathrm{~s}$.

A measured indoor $\mathrm{PM}_{10}$ profile in Taipei Metropolis is used as the initial condition of the PM size distribution. The measured profile follows a lognormal distribution with a geometric mean diameter of $1.71 \mu \mathrm{m}$ and a geometric standard deviation of 2.47. The measured profile is divided into ten size groups from aerodynamic diameter ranging from 0.1 to $10 \mu \mathrm{m}$. The PM concentration is assumed to be a constant within each group. At the beginning of particle release, particles are distributed uniformly and statically in each room. The initial PM mass concentrations in the living room, kitchen, two bedrooms and bathroom are $100,200,30$ and $100 \mu \mathrm{g} / \mathrm{m}^{3}$, respectively, which are based on the past indoor pollution researches [30-32]. Thus, the initial building-averaged $\mathrm{PM}_{10}, \mathrm{PM}_{2.5}$ and $\mathrm{PM}_{1}$ mass concentrations are $89.1,5.6,0.03 \mu \mathrm{g} / \mathrm{m}^{3}$, respectively. Chang et al. [23] has conducted the sensitivity analysis on the released particle number that provided sufficient numerical accuracy and acceptable computing time. It is found that at least 8000 sample particles are required. Based on the initial PM size profile, initial PM mass concentrations and room size, the particle mass carried by each sample particle for each size group and each room for 8000 sample particles is calculated and is listed in Table 1 of Chang et al. [23].

After clean outdoor air flowing into the building, particles are redistributed. PM concentrations are obtained from the simulated results of particle trajectories. $\mathrm{PM}_{10}, \mathrm{PM}_{2.5}$, and $\mathrm{PM}_{1}$ are determined by numerically integrating the appropriately weighted moment of the respective particle size group. It should be noted that, in the Lagrangian particle tracking process, the determination of time step size is based on the particle diameter. The time step is selected as one order smaller than the relaxation time of particles, and the time step is constant for each size group. 600 ensembles are undertaken to obtain the ensemble-averaged trajectories for each sample particle at each time step.

\section{Results and discussions}

\subsection{Indoor airflow characteristics}

By means of the LES procedure and turbulent statistics, the instantaneous and time-average airflow velocities of the 617,000 non-uniform grids are determined. To realize airflow characteristics of the multi-room building, the indoor airflow pattern with the airflow streamlines, mean velocities and root mean square (RMS) fluctuating velocity contours along the streamwise $(y)$ direction at a representative plane of $1.6 \mathrm{~m}$ high from the floor are displayed in Fig. 2. Meanwhile, the time-averaged ventilation rate for each opening in the building is shown in Fig. 3. The airflow paths of the entire building for the four ventilation patterns are also depicted in Fig. 3. It can be seen from Figs. 2a and 3a that the momentum of the incoming airflow is hindered by the interior partitions in the streamwise direction so that the airflow paths are swerved into the lateral $(x)$ and vertical $(z)$ directions. For this reason, all of the rooms in the building can receive sufficient airflow exchange and develop complete double-sided airflow paths from incoming to outgoing for full-open ventilation. The ratio of the outlet-to-inlet opening size is as large as 1.67 . This phenomenon also brings high RMS fluctuating velocities in the entire building. Regarding pass-through ventilation, due to the limited flow path in the lateral direction, the inflow streams coming from the windward windows are restricted to flow toward the leeward ones so that its airflow pattern behaves like a piston flow. It is shown in Figs. $2 \mathrm{~b}$ and $3 \mathrm{~b}$ that all of the rooms except the bathroom have good ventilation. The bathroom only receives single-sided ventilation.

In the case of right short-circuit ventilation, because there is only one outflow window adjacent to the inflow window in the living room, a succinct airflow path from entry to exit is established to exhibit the so-called short-circuit effect. It can be seen in Figs. $2 \mathrm{c}$ and $3 c$ that the lateral-side deviation of the mean inflow velocity distribution in the living room is attributed to the strong shortcircuit effect rather than the impediment of the interior partitions. High mean velocities and RMS fluctuating velocities are found in the windward rooms (i.e., the living room and bedroom I) where receive good airflow exchange. The bedroom II, bathroom and kitchen receive single-sided ventilation. As to left short-circuit ventilation as shown in Figs. $2 \mathrm{~d}$ and $3 \mathrm{~d}$, two incoming streams together with the short-circuiting effect lead to good air exchange in the windward rooms and poor air exchange in the leeward rooms (i.e., the kitchen and bedroom II). In contrast with right short-circuit ventilation, the bathroom in left short-circuit ventilation receives better airflow exchange since the only outlet is in it. Single-sided ventilation can be found in the kitchen and bedroom II. Therefore, the above results reveal that under different ventilation patterns with the same air change rate in the building, the mean velocity and RMS fluctuating velocity characteristics are quite different.

In Table 2 , the building-averaged mean velocities and the building-averaged relative turbulent intensities (the ratio of the RMS fluctuating velocities to the time-averaged velocities) are calculated by spatially integrating the simulated results in Fig. 2 for the entire building. It is observed from Table 2 that the lowest values of the mean velocities and $x-y-z$ velocity components are given by right short-circuit ventilation, due to the strong shortcircuiting effect. The highest mean velocities and $x-y-z$ velocity components can be found for pass-through ventilation, which comes from the piston-like flow pattern. Besides, left short-circuit ventilation leads to high mean $x$-direction velocity because all 
(a)

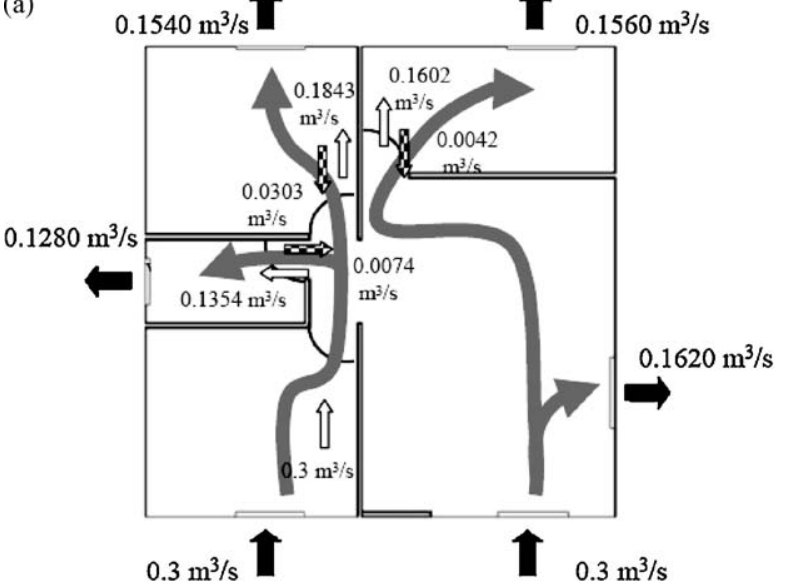

(c)

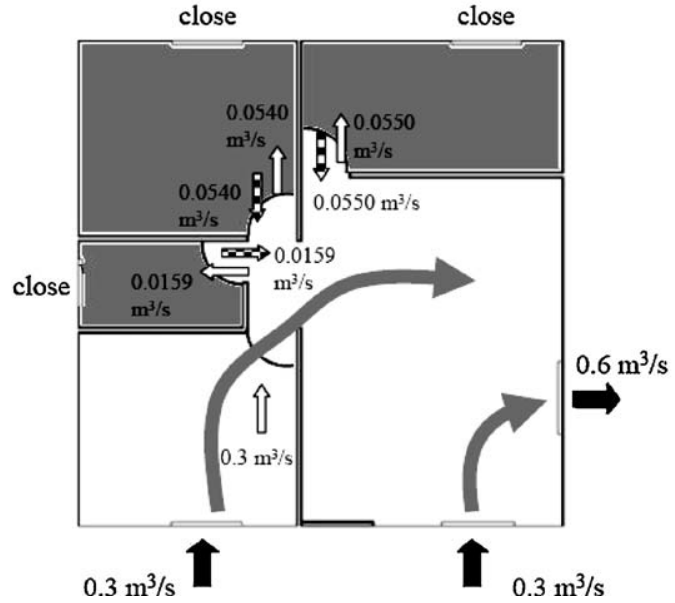

(b)
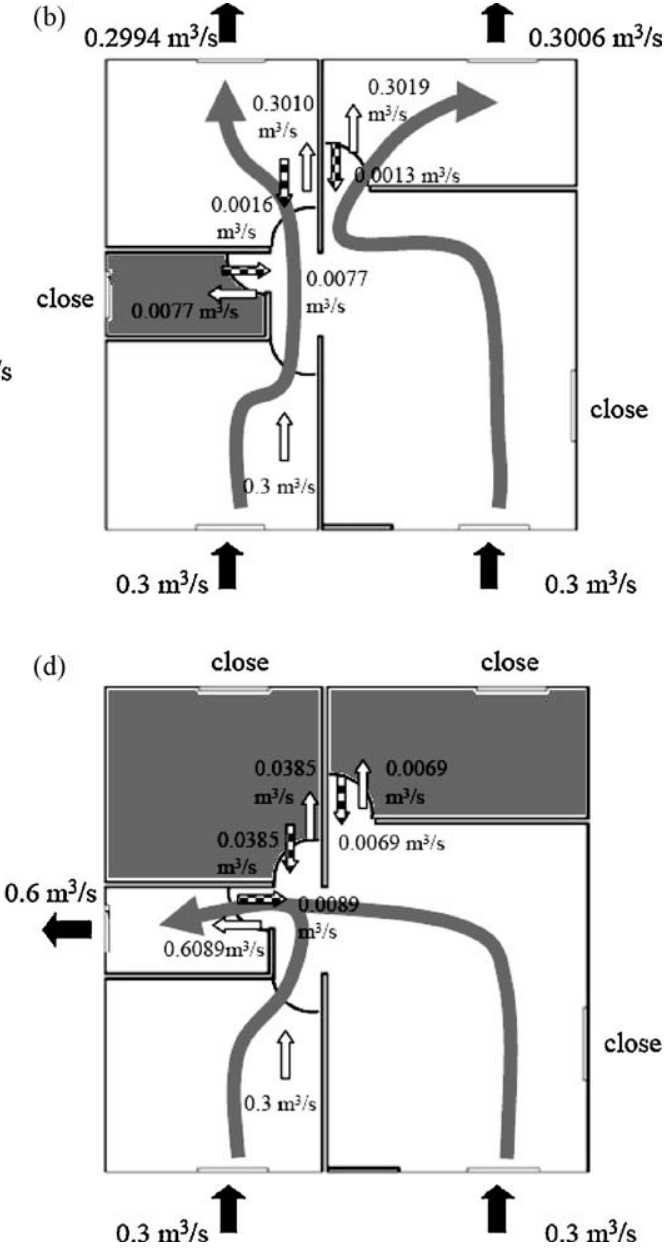

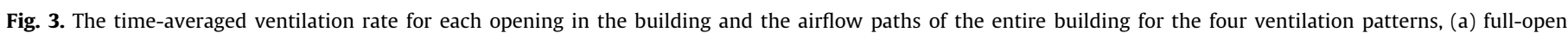

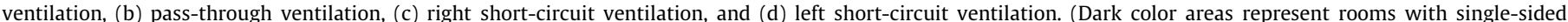
ventilation).

Table 2

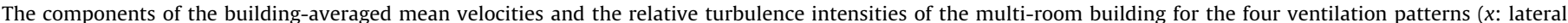
direction, $y$ : streamwise direction, $z$ : vertical direction).

\begin{tabular}{|c|c|c|c|c|c|c|c|}
\hline \multirow[t]{2}{*}{ Ventilation pattern } & \multicolumn{4}{|c|}{ Building-averaged mean velocities (m/s) } & \multicolumn{3}{|c|}{ Relative turbulence intensities (\%) } \\
\hline & Mean velocity component & $x$ & $y$ & $z$ & $x$ & $y$ & $z$ \\
\hline Full-open & 0.050 & 0.018 & 0.032 & 0.018 & 21.3 & 14.9 & 20.7 \\
\hline Pass-through & 0.054 & 0.020 & 0.036 & 0.019 & 12.0 & 8.0 & 11.7 \\
\hline Right short-circuit & 0.040 & 0.015 & 0.027 & 0.014 & 11.7 & 8.2 & 10.7 \\
\hline Left short-circuit & 0.050 & 0.021 & 0.029 & 0.017 & 9.9 & 8.1 & 10.6 \\
\hline
\end{tabular}

airflow paths are towards the only outlet located in bathroom along the lateral direction. The relative turbulent intensity under full-open ventilation is about $50 \%$ higher than the other ventilation patterns.

\subsection{Particulate matter transport behavior}

Through the calculated PM trajectories at each tracking time, the time variations of $\mathrm{PM}_{10} / \mathrm{PM}_{2.5} / \mathrm{PM}_{1}$ mass concentrations are obtained by using Eq. (5). Fig. 4 gives dimensionless mass concentrations of $\mathrm{PM}_{10}, \mathrm{PM}_{2.5}$ and $\mathrm{PM}_{1}$ in each room of the building for the four ventilation patterns at the 10th minute of the tracking time. In Fig. 4a, for full-open ventilation, all of the rooms receive double-sided ventilation. $\mathrm{PM}_{10}$ mass concentrations in all the rooms quickly decline to $10 \%$ of the initial concentration or below at the 10 th minute. For finer particles, however, $\mathrm{PM}_{2.5}$ mass concentrations slowly decrease with time, and $\mathrm{PM}_{1}$ mass concentrations cannot be effectively reduced. In Fig. $4 \mathrm{~b}$, in the case of pass-through ventilation, due to the limited flow path in the lateral direction, indoor particles carried by the strong piston-like airflow have to go through the leeward rooms (i.e., the kitchen and bedroom II) and then escape out of the building. This phenomenon brings on the short-term aggregation of PM mass concentrations in the leeward rooms. In comparison with full-open ventilation, passthrough ventilation has the inferior efficiency to remove particles from the building.

Regarding right short-circuit ventilation, the only outlet is located in the living room, giving the so-called short-circuiting effect. As such, the living room has good PM removal efficiency. However, the bedroom II, bathroom and kitchen receive poor single-sided ventilation, which causes high PM concentrations, as shown in Fig. 4c. In Fig. 4d, as to left short-circuit ventilation, as a 

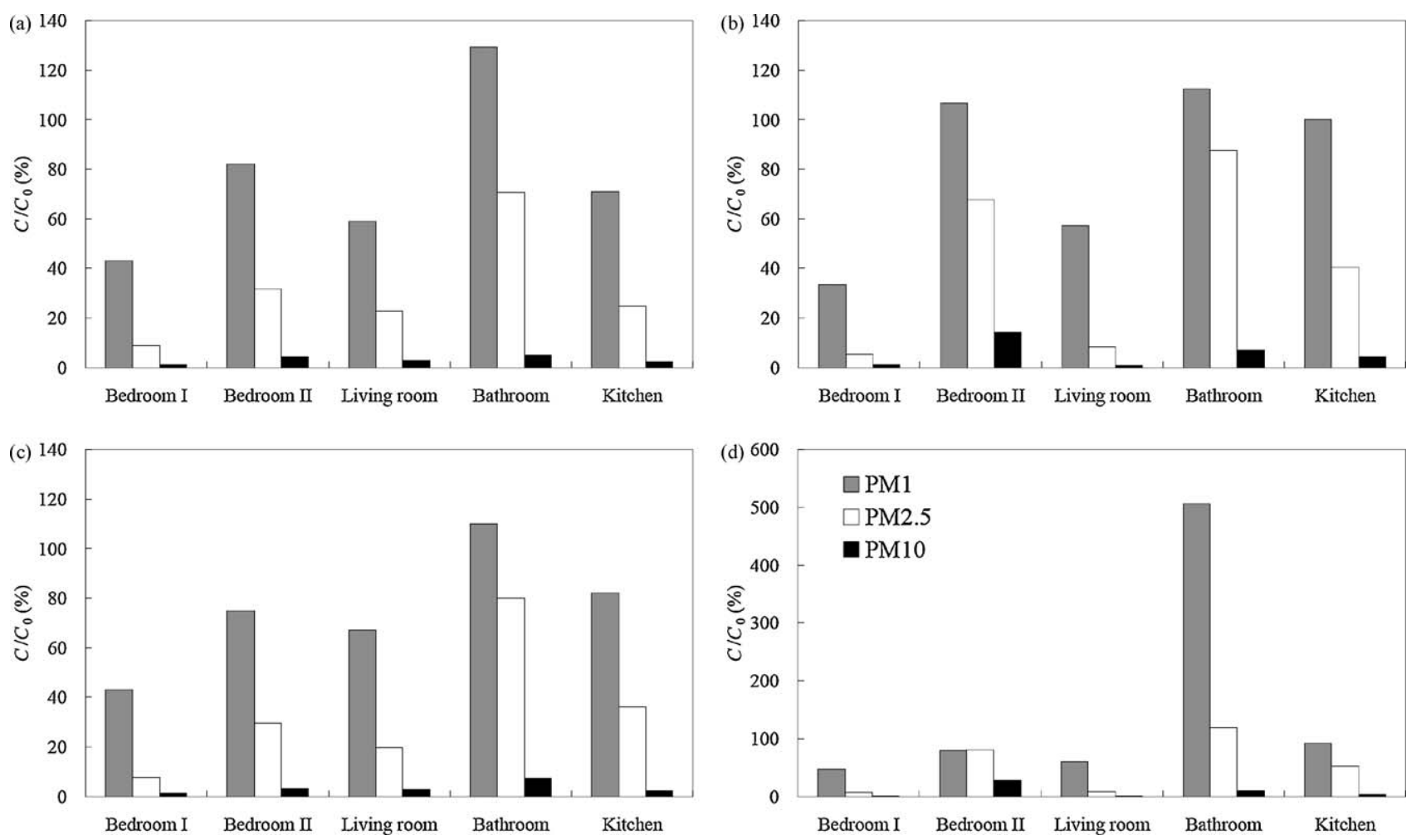

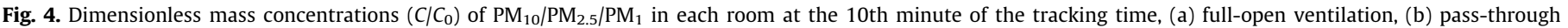
ventilation, (c) right short-circuit ventilation, and (d) left short-circuit ventilation. ( $C_{0}$ is the initial mass concentration in each room).

result of large inlet size and small outlet size in the airflow paths, $\mathrm{PM}$ is accumulated in the bathroom and high $\mathrm{PM}_{10} / \mathrm{PM}_{2.5} / \mathrm{PM}_{1}$ concentrations are observed due to the strong particle immigration and weak particle migration. $\mathrm{PM}_{1}$ concentration in the bathroom even reaches up to $500 \%$ of the initial value, indicating serious particle accumulation. In addition, the short-circuiting effect also induces high PM concentrations in the rooms with single-sided ventilation, i.e., the kitchen and bedroom II. Therefore, left shortcircuit ventilation gives the worst indoor PM removal efficiency among the four ventilation patterns.

\subsection{Removal efficiency of $P M_{10} / P M_{2.5} / P M_{1}$ mass concentration}

Based on the time variation of $\mathrm{PM}_{10} / \mathrm{PM}_{2.5} / \mathrm{PM}_{1}$ mass concentrations in each room, PM levels are spatially averaged for the entire building to obtain the building-averaged removal efficiencies of $\mathrm{PM}_{10}, \mathrm{PM}_{2.5}$, and $\mathrm{PM}_{1}$ at the 10th minute of the tracking time, as shown in Table 3. Obviously, all of the ventilation patterns give good removal efficiency in $\mathrm{PM}_{10}$ (96.0-97.2\%) compared to $\mathrm{PM}_{2.5}$ (71.175.6\%) and $\mathrm{PM}_{1}(20.0-36.4 \%)$. This result is responsible for the reason that coarse particles $(>2 \mu \mathrm{m})$ possess larger inertia and relaxation time to maintain their velocities for longer time duration, so that they are easier to be driven out of the building than fine particles. On the contrary, fine particles ( $\leqq 2 \mu \mathrm{m}$ ) having smaller inertia and relaxation time are more easily influenced by the

Table 3

Removal efficiencies of $\mathrm{PM}_{10} / \mathrm{PM}_{2.5} / \mathrm{PM}_{1}$ for the four ventilation patterns.

\begin{tabular}{llcr}
\hline Ventilation pattern & \multicolumn{2}{l}{ Removal efficiency (\%) } \\
\cline { 2 - 4 } & $\mathrm{PM}_{10}$ & $\mathrm{PM}_{2.5}$ & $\mathrm{PM}_{1}$ \\
\hline Full-open & 97.2 & 75.6 & 36.4 \\
Pass-through & 96.8 & 75.5 & 28.8 \\
Right short-circuit & 97.0 & 74.0 & 29.6 \\
Left short-circuit & 96.0 & 71.1 & 20.0 \\
\hline
\end{tabular}

surrounding complex indoor airflow patterns of the building such as various length-scale vortexes, incoming momentum jets, and circulating flows, and are trapped in eddies indoors. This phenomenon can result in worse $\mathrm{PM}_{2.5}$ and $\mathrm{PM}_{1}$ removal efficiency of multiroom buildings. As a result, cross-flow displacement ventilation is not an effective way to remove fine particles out of multi-room buildings. It is important to note that fine particles suspending in indoor space is harmful to human health and induces influence on the respiratory system of human beings. Thus, it is not enough to use $\mathrm{PM}_{10}$ level as the only indoor PM index.

Moreover, it can be observed from Table 3 that different ventilation patterns can result in almost identical $\mathrm{PM}_{10}$ removal efficiency, but different results of $\mathrm{PM}_{2.5}$ and $\mathrm{PM}_{1}$ removal efficiency. Full-open ventilation and left short-circuit ventilation, having the highest and lowest outlet-to-inlet opening size ratio, respectively, receive the best and worst $\mathrm{PM}_{2.5} / \mathrm{PM}_{1}$ removal efficiency, respectively. The variation ranges in $\mathrm{PM}_{2.5}$ and $\mathrm{PM}_{1}$ removal efficiency for these two ventilation patterns are $4.5 \%$ and $16.4 \%$, respectively.

\subsection{Particle size distribution}

As a consequence of the efficient removal of coarse particles, the suspended particle number fraction for particle sizes larger than $4 \mu \mathrm{m}$ apparently approaches to zero for the four ventilation patterns. However, fine particles reeve hither and thither in the building owing to the effect of the complex indoor airflow patterns in the multi-room building. This causes a swifter shift of the particle size distribution towards smaller size. Taking the living room as an example, the present study compares the initial particle size distribution and the particle size distributions at the 10th minute of the tracking time for the four ventilation patterns. The geometric mean diameters of the particle size profiles in the living room for full-open, pass-through, right short-circuit, and left shortcircuit ventilation are $1.43,0.62,1.51$, and $0.62 \mu \mathrm{m}$, respectively, which can be explained by using Fig. 3 . 

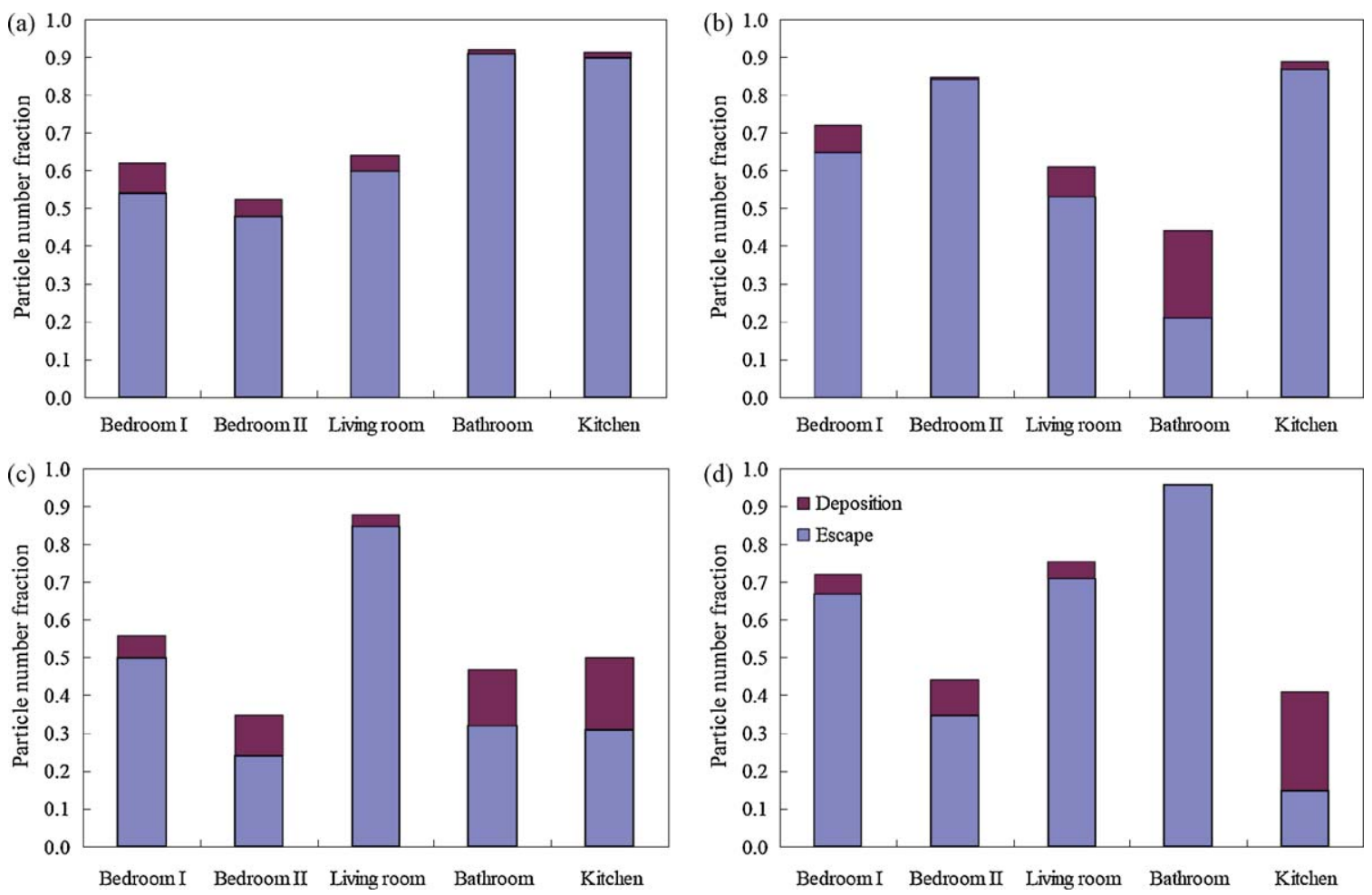

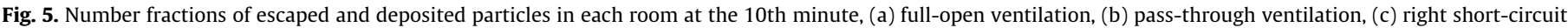
ventilation, and (d) left short-circuit ventilation.

For full-open ventilation, the living room receives complete double-sided airflow paths from incoming to outgoings, as shown in Fig. 3a. The geometric mean diameter in the living room is thus reduced from the initial value of $1.71-1.43 \mu \mathrm{m}$ at the 10 th minute. Regarding right short-circuit ventilation in Fig. $3 c$, because of the strong short-circuiting effect together with the only outlet located in the living room, particles coming from other rooms have to go through the living room and then escape out of the building. The geometric mean diameter is thus up to $1.51 \mu \mathrm{m}$. In the cases of pass-through and left short-circuit ventilation, their airflow paths in the living room are similar (see Fig. $3 \mathrm{~b}$ and d), which also gives the similar geometric mean diameter. Indoor PM in the living room can easily migrate to other leeward rooms. Their geometric mean diameter is further reduced to $0.62 \mu \mathrm{m}$.

\subsection{Particle removal mechanism}

In the present study, indoor particles are redistributed after outdoor air flowing into the building. Particles would suspend in the air, migrate to other rooms, settle down to floors, inertially impact or intercept on walls or ceilings, or escape out of the building. The above particle transport behaviors are usually classified into four particle transport modes, i.e., suspension, migration (carried to the neighboring room by airflow), deposition and escape. Particle deposition and escape are usually regarded as particle removal mechanism $[19,20,23,33]$. It should be noted that particle deposition is the combined results of inertial impaction, turbulence-eddy impaction, interception, gravitational sedimentation, and the Brownian motion, which can be thoughtfully simulated by the present numerical models [19,20,23]. Particle suspension and migration, have been investigated in the previous three sections. The effect of ventilation pattern on particle removal mechanism will be discussed next.

Fig. 5 gives the number fractions of escaped and deposited particles in each room at the 10th minute for the four ventilation patterns. Regarding full-open ventilation, all of the rooms can receive sufficient double-sided ventilation, resulting in the highest outlet-to-inlet opening size ratio. The amount of escaped particles in each room is eight times more than that of deposited particles, as shown in Fig. 5a. Particle escape is the major mechanism for removing indoor PM. As to the case of pass-through ventilation, because of the limited flow path in the lateral direction, all of the rooms except the bathroom receive good double-sided ventilation. As such, in Fig. 5b, high amount of deposited particles is only observed in the bathroom. Apparently, particle deposition is the most important removal mechanism for the bathroom which has single-sided ventilation, whereas particle escape is the major removal mechanism for other rooms. In Fig. $5 c$, the only outlet is located in the living room for right short-circuit ventilation. The poor single-sided ventilation spaces (the bedroom II, bathroom and kitchen) have high amount of deposited particles. For left short-circuit ventilation as shown in Fig. 5d, high deposition proportion can also be found in the single-sided ventilation rooms, especially in the kitchen. Consequently, the above results reveal that particle escape is the major mechanism to remove particles for rooms with double-sided ventilation. For rooms having better particle escape, particle deposition decreases. On the contrary, a higher amount of deposited particles than escaped particles is found in rooms with single-sided ventilation.

\section{Conclusions}

According to the simulated results, the present research has led to the following conclusions:

(1) Though the air change rate of the building is the same, airflow characteristics and PM transport behaviors are quite different for various ventilation patterns. It is observed that right shortcircuit ventilation pattern gives the lowest value of the mean velocity and $x-y-z$ velocity components. The highest mean 
velocities and $x-y-z$ velocity components can be found for pass-through ventilation, resulting from its piston-like flow pattern. Besides, the relative turbulent intensity under fullopen ventilation pattern is about $50 \%$ higher than the other ventilation patterns.

(2) For the four ventilation patterns herein used, the removal efficiencies of $\mathrm{PM}_{10}$ are all found to be much better than those of $\mathrm{PM}_{2.5}$ and $\mathrm{PM}_{1}$. Fine particles $\left(\mathrm{PM}_{1}\right.$ and $\left.\mathrm{PM}_{2.5}\right)$ are difficult to be removed out and would cause serious adverse healthy problems for indoor occupants.

(3) Different ventilation patterns can result in almost identical $\mathrm{PM}_{10}$ removal efficiency, but different results for $\mathrm{PM}_{2.5}$ and $\mathrm{PM}_{1}$ removal efficiency. Thus, it is not enough to use $\mathrm{PM}_{10}$ level as the only indoor PM index.

(4) Full-open ventilation, giving the highest outlet-to-inlet opening size ratio, is the most effective ventilation pattern to lower down indoor PM among the four ventilation patterns. Left short-circuit ventilation, having the lowest outlet-to-inlet opening size ratio, gives the worst indoor PM removal efficiency.

(5) Particle escape is the most important mechanism to remove particles for rooms with double-sided ventilation, whereas particle deposition is the major removal mechanism for singlesided ventilation rooms. For rooms having better particle escape, particle deposition decreases.

\section{References}

[1] C.Y. Chao, K.K. Wong, Residential indoor $\mathrm{PM}_{10}$ and $\mathrm{PM}_{2.5}$ in Hong Kong and the elemental composition, Atmospheric Environment 36 (2002) 265-277.

[2] G.D. Thurston, K. Ito, C.G. Hayes, D.V. Bates, M. Lippmann, Respiratory hospital admissions and summertime haze air pollution in Toronto, Ontario: consideration of the role of acid aerosols, Environmental Research 65 (1994) 271-290.

[3] D.E. Abbey, B.E. Ostro, F. Petersen, R.J. Burchette, Chronic respiratory symptoms associated with estimated long-term ambient concentrations of fine particulates less than 2.5 microns in aerodynamic diameter $\left(\mathrm{PM}_{2.5}\right)$ and other air pollutants, Journal of Exposure Analysis and Environmental Epidemiology 5 (1995) 137-159.

[4] C. Li, Elemental composition of residential indoor $\mathrm{PM}_{10}$ in the urban atmosphere of Taipei, Atmospheric Environment 28 (1994) 3139-3144.

[5] N. Hirosihi, I. Masanori, S. Manabu, K. Sadanori, O. Masaji, A new approach based on a covariance structure model to source apportionment of indoor fine particles in Tokyo, Atmospheric Environment 28 (1994) 631-636.

[6] C.W.Tung, Y.H. Chao, J. Burnett, S.W. Pang, Y.M. Lee, A territory wide survey on indoor particulate level in Hong Kong, Building and Environment 34 (1999) 213-220.

[7] C. Lanchenmyer, G.M. Hidy, Urban measurements of outdoor-indoor $\mathrm{PM}_{2.5}$ concentrations and personal exposure in the deep south. Part I. pilot study of mass concentrations for nonsmoking subjects, Aerosol Science and Technology 32 (2000) 34-51.

[8] P. Koutrakis, S.N. Sax, J.A. Sarnet, B. Coull, P. Demokritou, P. Oyola, J. Garcia, E. Gramsch, Analysis of PM10, PM2.5, and PM2.5-10 Concentrations in Santiago, Chile, form 1989 to 2001, Journal of the Air and Waste Management Association 55 (2005) 342-351.

[9] W. Lu, A.T. Howarth, Numerical analysis of indoor aerosol particle deposition and distribution in two-zone ventilation system, Building and Environment 31 (1996) 41-50.
[10] W. Lu, A.T. Howarth, N. Adam, S.B. Riffat, Modeling and measurement of airflow and aerosol particle distribution in a ventilated two-zone chamber, Building and Environment 31 (1996) 417-423.

[11] W. Zhang, Q. Chen, Large eddy simulation of indoor airflow with a filtered dynamic subgrid scale, International Journal of Heat and Mass Transfer 43 (2000) 3219-3231.

[12] Y. Jiang, Q. Chen, Study of natural ventilation in buildings by large eddy simulation, Journal of Wind Engineering and Industrial Aerodynamics 89 (2001) 11551178.

[13] J.D. Posner, C.R. Buchanan, D. Dunn-Rankin, Measurement and prediction of indoor air flow in a model room, Energy and Buildings 35 (2003) 515-526.

[14] H. Lee, H.B. Awbi, Effect of internal partitioning on indoor air quality of rooms with mixing ventilation-basic study, Building and Environment 39 (2004) 127141.

[15] B. Zhao, Y. Zhang, X. Li, X. Yang, D. Huang, Comparison of indoor aerosol particle concentration and deposition in different ventilated rooms by numerical method, Building and Environment 39 (2004) 1-8.

[16] C. Beghein, Y. Jiang, Q.Y. Chen, Using large eddy simulation to study particle motions in a room, Indoor Air 15 (2005) 281-290.

[17] T.J. Chang, Numerical evaluation of the effect of traffic pollutant on indoor air quality of a naturally ventilated building, Journal of the Air and Waste Management Association 52 (2002) 1043-1053.

[18] T.J. Chang, M.Y. Huang, Y.T. Wu, C.M. Liao, Quantitative prediction of traffic pollutant transmission into buildings, Journal of Environmental Science and Health Part A 38 (2003) 1025-1040.

[19] T.J. Chang, H.M. Kao, Y.F. Hsieh, Numerical study of the effect of ventilation pattern on coarse, fine, and very fine particulate matter removal in partitioned indoor environment, Journal of the Air and Waste Management Association 57 (2007) 179-189.

[20] T.J. Chang T.S. Hu, Transport mechanism of airborne particulate matter in partitioned indoor environment, Building and Environment 43 (2008) 886-895.

[21] A.C.K. Lai, K. Wang, F.Z. Chen, Experimental and numerical study on particle distribution in a two-zone chamber, Atmospheric Environment 42 (2008) 17171726.

[22] C.Y.H. Chao, M.P. Wan, G.N. Sze To, Transport and removal of expiratory droplets in hospital ward environment, Aerosol Science and Technology 42 (2008) $377-$ 394.

[23] T.J. Chang, Y.F. Hsieh, H.M. Kao, Numerical investigation of airflow pattern and particulate matter transport in naturally ventilated multi-room buildings, Indoor Air 16 (2006) 136-152.

[24] B.E. Launder, D.B. Spalding, The numerical computation of turbulent flow, Computer Methods in Applied Mechanics and Engineering 3 (1974) 269-289.

[25] A. Li, G. Ahmadi, Deposition of aerosols on surfaces in a turbulent channel flow, International Journal of Engineering Science 31 (1993) 435-451.

[26] T.J. Chang, B.C. Yen, Gravitational fall velocity of sphere in viscous fluid, Journal of Engineering Mechanics, ASCE 124 (1998) 1193-1199.

[27] T.J. Chang, H.M. Kao, Y.T. Wu, W.H. Huang, Transport mechanisms of coarse, fine, and very fine particulate matter in urban street canopies with different building layouts, Journal of the Air and Waste Management Association 59 (2009) 196206.

[28] K.C. Chung, Three-dimensional analysis of airflow and contaminant particle transport in a partitioned enclosure, Building and Environment 34 (1999) 7-17.

[29] ICEM CFD Hexa, ANSYS Inc., Canonsburg, PA, USA, http://www.ansys.com.

[30] S.Y. Lu, Narrowest particle size distributions in aerosol processes, Journal of the Chinese Institute of Chemical Engineers 27 (1996) 71-78.

[31] K.C. Chung, C.M. Chiang, W.A. Wang, Predicting containment particle distributions to evaluate the environment of lavatory with floor exhaust ventilation, Building and Environment 32 (1997) 149-159.

[32] L. Wallace, C. Howard-Reed, Continuous monitoring of ultrafine, fine, and coarse particles in a residence for 18 months in 1999-2000, Journal of the Air and Waste Management Association 52 (2002) 828-844.

[33] W.C. Hinds, Aerosol Technology: Properties, Behavior, and Measurement of Airborne Particles, Wiley-Interscience Publication, New York, USA, 1999. 